\title{
Resultados maternos e perinatais de dez anos de assistência obstétrica a portadoras do vírus da imunodeficiência humana
}

\author{
Maternal and perinatal results in ten years of obstetrical care to human \\ immunodeficiency virus-infected women
}

Victor Hugo Melo ${ }^{1}$, Regina Amélia Lopes Pessoa Aguiar ${ }^{1}$, Ana Christina de Lacerda Lobato ${ }^{2}$, Ines Katerina Damasceno Cavallo ${ }^{2}$, Fabiana Maria Kakehasi ${ }^{3}$, Roberta Maia de Castro Romanelli ${ }^{3}$, Jorge Andrade Pinto ${ }^{1}$

\section{RESUMO}

Objetivos: avaliar a transmissão vertical do vírus da imunodeficiência humana (HIV) e os fatores de risco associados à infecção perinatal. Métodos: estudo descritivo de 170 gestantes infectadas pelo HIV e seus 188 recém-nascidos, admitidas na Maternidade do Hospital das Clínicas da UFMG, no período de junho de 1994 a setembro de 2004. Foram analisados as características demográficas, o perfil sorológico e a via de parto das gestantes, assim como os resultados perinatais. As crianças foram acompanhadas por período de 18 meses após o nascimento. Os dados foram armazenados e analisados no Epi-Info, Versão 6.0. Estabeleceu-se intervalo de confiança a 95\% $(\mathrm{p}<0,05)$. Resultados: o diagnóstico da infecção pelo HIV foi confirmado durante a gestação em $84(45,4 \%$ ) pacientes. A carga viral era inferior a 1000 cópias $/ \mathrm{mL}$ em $60,4 \%$ das pacientes. O esquema predominante de uso dos anti-retrovirais foi a terapia tríplice (65,5\%). Foi alta a taxa de cesariana: 79,5\%. A taxa de prematuridade foi 18,2\%. Entre os 188 recém-natos houve 184 (97,8\%) nativivos e quatro (2,2\%) mortes perinatais. Dos nascidos vivos, 97,8\% receberam zidovudina após o nascimento. A taxa global de transmissão materno-fetal global foi 3,8\%. As taxas de transmissão vertical do vírus, por período, foram: 60\%, até 1996; 28\%, entre 1996 e 1998; 0,68\%, entre 1999 e 2004 . Não foram encontrados fatores de risco significativamente associados à infecção perinatal pelo HIV, devido ao pequeno número de recém-nascidos infectados $(n=6)$. Conclusão: houve grande redução da transmissão vertical do HIV no período analisado. A taxa atual de transmissão é zero, confirmando que, adotando-se medidas adequadas, pode-se prevenir a transmissão perinatal do vírus.

PALAVRAS-CHAVE: Infecções por HIV; Transmissão vertical de doença; Resultado da gravidez; Gravidez de alto risco; Complicações infecciosas da gravidez

\section{ABSTRACT}

Purpose: to evaluate human immunodeficiency virus (HIV) vertical transmission and risk factors related to perinatal infection. Methods: descriptive study of 170 HIV-infected pregnant women and their 188 neonates, admitted from June 1994 to September 2004 at the "Maternidade do Hospital das Clínicas da UFMG". Demographic characteristics, mother's serologic state, mode of delivery and perinatal results were analyzed. Children were followed for 18 months after birth. Data were stored and analyzed by Epi-Info, version 6.0. Confidence interval was established at 95\% ( $<<0.05)$. Results: HIV infection was confirmed in $84(45.4 \%)$ patients during gestation. Viral load was below 1,000 copies/mL in $60.4 \%$ patients. Highly active antiretroviral therapy was the predominant antiretroviral regimen (65.5\%). C-section rate was high: 79.5\%. Prematurity rate was $18.2 \%$. There were $184(97.8 \%)$ live births and four (2.2\%) perinatal deaths among 188 neonates. Among live neonates $97.8 \%$ received zidovudine after birth. Global mother-to-child transmission rate was 3.8\%. Virus vertical transmission rates for each period were: 60\%, until 1996; 28\% between 1996 and 1998; 0.68\%, between 1999 and 2004. Significant risk factors were not found related to perinatal HIV-infection because there was a small number of infected neonates $(n=6)$. Conclusion: there was a great reduction of HIV vertical transmission during the analyzed period. Current transmission rate is zero. This confirms that by adopting adequate measures perinatal virus transmission can be prevented.

KEYWORDS: HIV infections; Disease transmission, vertical; Pregnancy outcome; Pregnancy, high risk ; Pregnancy complications, infectious.

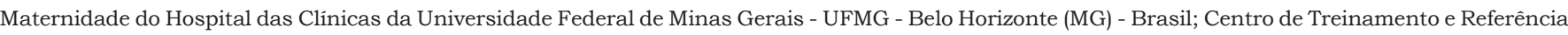
para Doenças Infecciosas e Parasitárias Orestes Diniz Prefeitura Municipal de Belo Horizonte (MG) - Brasil.

1 Professor Adjunto da Faculdade de Medicina da Universidade Federal de Minas Gerais - UFMG - Belo Horizonte (MG) - Brasil.

2 Residente do Hospital das Clinicas da Universidade Federal de Minas Gerais - UFMG - Belo Horizonte (MG) - Brasil.

3 Pediatra do Hospital das Clínicas da Universidade Federal de Minas Gerais - UFMG - Belo Horizonte (MG) - Brasil.

Correspondência: Victor Hugo de Melo

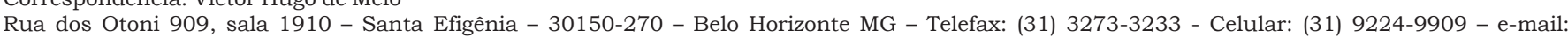
victormelo@terra.com.br 


\section{Introdução}

No final de 2004, estimou-se que 17,6 milhões de mulheres em todo o mundo eram portadoras do virus da imunodeficiência humana (HIV). Por outro lado, 640 mil crianças com menos de 15 anos foram infectadas naquele ano, sendo que em mais de $90 \%$ delas a infecção ocorreu durante a gravidez ou no período do aleitamento materno. Além disso, havia na América Latina 1,7 milhões de pessoas vivendo com o virus, das quais $36 \%(612$ mil) eram mulheres ${ }^{1}$.

Em 1994 foram publicados os resultados do primeiro ensaio clínico randomizado que avaliou a eficácia do uso profilático da zidovudina (AZT) durante a gravidez, no parto e para o recém-nascido - com o objetivo de reduzir a transmissão vertical do HIV (PACTG 076) ${ }^{2}$. Desde então vários fatores de risco foram identificados e medidas foram adotadas com o mesmo objetivo ${ }^{3-8}$. O uso combinado dos anti-retrovirais (ARV) ${ }^{3,4}$, a via de parto de acordo com a carga viral materna ${ }^{5}$, e a substituição do aleitamento materno por fórmula láctea ${ }^{6}$ são considerados determinantes na redução da transmissão vertical do vírus. No Brasil, o seguimento das orientações internacionais de cuidados às gestantes soropositivas e seus recémnascidos tem contribuído para a redução gradual das taxas de transmissão vertical ${ }^{9-11}$. No entanto, outros países, especialmente na África subsaariana, onde o acesso aos ARV é limitado e o aleitamento materno é prática comum, ainda persistem altas taxas de transmissão vertical do virus ${ }^{12}$.

Estudo realizado em países desenvolvidos demonstrou que a gravidez não exerce efeito sobre a progressão da doença materna ${ }^{13}$, mas existem controvérsias quanto aos resultados perinatais. Enquanto alguns estudos não detectaram aumento na freqüência de prematuridade, baixo peso ao nascer e restrição do crescimento fetal ${ }^{14,15}$, outros verificaram taxas mais altas de parto pré-termo, variando com o esquema de ARV utilizado, sem impacto nas taxas de morbidade dos recém-nascidos ${ }^{16}$. Infelizmente, nos países em desenvolvimento, as taxas de prematuridade e baixo peso ao nascer podem ser mais elevadas para os recém-nascidos de mães soropositivas devido a fatores sociais e econômicos adversos ${ }^{17,18}$.

O Hospital das Clínicas da Universidade Federal de Minas Gerais (UFMG) fez o primeiro atendimento de gestante sabidamente infectada pelo HIV em 1994. A partir de 1998 tornou-se referência para o seguimento dessas gestantes. Os marcos na assistência obstétrica prestada pela instituição foram: utilização rotineira dos ARV, defini- ção da via de parto conforme a quantificação da carga viral materna no período anteparto e uso da fórmula láctea pelo recém-nascido, evitando o aleitamento materno, conforme o protocolo do Ministério da Saúde ${ }^{19}$.

O objetivo deste estudo foi avaliar os resultados de aplicação dos protocolos adotados pelo Ministério da Saúde na redução da transmissão vertical do HIV e os fatores de risco associados à infecção perinatal em gestantes HIV-infectadas.

\section{Métodos}

Realizou-se estudo descritivo de 170 gestantes soropositivas para o HIV atendidas na Maternidade do Hospital das Clínicas da UFMG, no período de junho de 1994 a setembro de 2004. Para a identificação destas pacientes foram consultados o livro de registro da maternidade, os dados do Sistema de Informação Perinatal do Centro LatinoAmericano de Perinatologia (CLAP) e os prontuários médicos do serviço.

Foram incluídas gestantes com diagnóstico da infecção pelo HIV, com dois testes ELISA positivos em amostras diferentes e um teste confirmatório (Western blot ou imunofluorescência indireta) positivo, acompanhadas no Pré-natal de Alto Risco do Hospital das Clínicas da UFMG. Foram excluídas aquelas que não tivessem os dados registrados no prontuário, ou apresentassem apenas um teste sorológico positivo para a infecção pelo HIV. Para a avaliação dos resultados considerou-se cada gestação, o que significa que algumas pacientes entraram mais de uma vez, e que suas variáveis foram analisadas individualmente em cada gravidez.

Para a coleta de dados utilizou-se questionário padronizado que foi pré-testado em amostra desta mesma população. As variáveis maternas relevantes foram: idade, estado civil, anos de estudo, tempo de diagnóstico do HIV, época do diagnóstico (durante ou fora da gestação), idade gestacional de início do pré-natal, uso de anti-retrovirais durante o pré-natal (terapêutico ou profilático), tempo de rotura de membranas, uso do AZT venoso (doses de ataque e manutenção), via de parto, contagem de linfócitos T CD4+ e carga viral próxima ao parto. As variáveis neonatais consideradas foram: idade gestacional ao nascimento (semanas completas), peso ao nascer (aferido imediatamente após o nascimento, em balança eletrônica digital), mortalidade perinatal e uso do AZT xarope.

As crianças foram acompanhadas no Centro de Treinamento e Referência em Doenças In- 
fecciosas e Parasitárias (CTR-DIP) Orestes Diniz, pela equipe pediátrica. Este ambulatório funciona em convênio entre a Prefeitura Municipal de Belo Horizonte, a Faculdade de Medicina e o Hospital das Clínicas da UFMG. O critério para diagnóstico final da presença da infecção pelo HIV nas crianças, até o primeiro semestre de 1997, era a presença de ELISA positivo após 18 meses de seguimento. A partir do segundo semestre de 1997 passou-se a utilizar a quantificação do HIV-RNA plasmático em duas ocasiões (entre dois e quatro meses e entre quatro e seis meses de idade).

Os dados foram armazenados e analisados no software Epi-Info, versão 6.0. A análise univariada foi realizada com cálculo de média, mediana e desvio padrão das variáveis contínuas e distribuição de freqüência das variáveis categóricas. Foi utilizado o $\chi^{2}$ ou o teste exato de Fisher para as comparações entre as variáveis categóricas na análise univariada, considerando-se o intervalo de confiança (IC) a 95\% $(\mathrm{p}<0,05)$. Os resultados foram analisados por períodos, e não por ano, para melhor descrever o comportamento da transmissão vertical e de outras variáveis.

Estes resultados fazem parte de estudo multicêntrico aprovado pelo Comitê de Ética em Pesquisa da Universidade Federal de Minas Gerais em 04/09/2002.

\section{Resultados}

Entre as 170 participantes do estudo ocorreram 185 gestações, sendo três gemelares, totalizando 188 recém-nascidos.

Entre as características demográficas da amostra destaca-se que a idade materna variou de 17 a 40 anos (mediana de 28 anos) e que a maioria das pacientes era casada ou tinha união estável $(65,4 \%)$. O tempo de infecção variou de zero a 12 anos (mediana de seis anos).

Para as pacientes que já sabiam da infecção antes da gravidez, a mediana do tempo de diagnóstico foi dois anos, variando de zero a 11 anos. O diagnóstico da infecção pelo HIV foi feito durante a gestação em 84 pacientes $(45,4 \%)$, sendo 53 $(32,7 \%)$ na gravidez atual e $31(16,7 \%)$ em gestações anteriores. A mediana da idade gestacional de início do pré-natal foi 19 semanas, variando de seis a 38 semanas.

A Tabela 1 apresenta os fatores de risco para a transmissão vertical do HIV. A contagem de linfócitos T CD4+ após a $34^{\mathrm{a}}$ semana variou de 8 a 2.772 células $/ \mathrm{mm}^{3}$ (mediana de 419 células/ $\left.\mathrm{mm}^{3}\right)$; a grande maioria $(85,7 \%)$ das pacientes apresentava contagem superior a 200 células/ $\mathrm{mm}^{3}$. A carga viral após a $34^{\mathrm{a}}$ semana foi quantificada em 154 pacientes e variou de indetectável (<50 cópias $/ \mathrm{mL}$ ) a 170.000 cópias/ $\mathrm{mL}$ (mediana de 313 cópias $/ \mathrm{mL}$ ), sendo que em $93(60,4 \%)$ era inferior a 1.000 cópias $/ \mathrm{mL}$.

\begin{tabular}{lcc} 
Tabela 1 - Fatores de risco para transmissão vertical do HIV & \multicolumn{3}{c}{ identificados nas gestantes } \\
participantes do estudo. & Pacientes & $\%$ \\
\hline Variáveis & $\mathbf{n}$ & \\
& 161 & - \\
\hline Contagem de linfócitos T CD4+ (células $/ \mathrm{mm}^{3}$ ) & 23 & 14,3 \\
$<200$ & 72 & 44,7 \\
200 a 499 & 66 & 41,0 \\
$>500$ & 154 & - \\
Carga viral (cópias/mL) & 61 & 39.6 \\
$<50$ & 32 & 20.8 \\
50 a 1000 & 61 & 39.6 \\
$\geq 1000$ & 185 & - \\
Uso dos ARV durante o pré-natal & 181 & 97,8 \\
Sim & 4 & 2,2 \\
Não & 52 & - \\
Rotura das membranas & 30 & 57,7 \\
Menos de quatro horas & 22 & 42,3 \\
Mais de quatro horas & 185 & - \\
Via de parto & 84 & 45,4 \\
Cesariana eletiva & 63 & 34,1 \\
Cesariana intraparto & 38 & 20,5 \\
Vaginal & 182 & - \\
Uso de AZT venoso intraparto (dose de ataque) & 166 & 91,2 \\
Sim & 16 & 8,8 \\
Não & & \\
\hline ARV = anti-retrovirais; AZT = zidovudina. & &
\end{tabular}

Nas 185 gestações, 181 mulheres $(97,8 \%)$ fizeram uso de ARV durante o pré-natal. Entre estas, $119(64,3 \%)$ iniciaram os ARV durante a gestação, a grande maioria para profilaxia da transmissão vertical. A mediana da idade gestacional ao início dos ARV foi 22 semanas (variação de 10 a 38 semanas). O esquema predominante foi a terapia tríplice $(65,5 \%)$. Quanto à dose de ataque da zidovudina (AZT), foram obtidas informações de 182 gestações.

Destas, 166 gestantes $(91,2 \%)$ receberam a primeira dose do AZT venoso intraparto. Entre as 16 pacientes que não receberam o medicamento venoso, os motivos encontrados foram: dois decessos fetais, oito parturientes admitidas em periodo expulsivo, três partos ocorridos antes de 1996, uma paciente submetida à cesariana em 
1995 e duas gestantes receberam AZT via oral. Entre as pacientes em que foi administrada a primeira dose do AZT venoso, 29 não receberam a dose de manutenção pelos seguintes motivos: foi realizada cesariana eletiva em 21 pacientes num período em que o protocolo não previa o intervalo de três horas entre a dose de ataque do AZT e a cirurgia; duas receberam o AZT intraparto por via oral; três tiveram parto vaginal antes de 1996 e outras três evoluíram rapidamente para o parto, não permitindo a realização da dose de manutenção.

Ainda na Tabela 1 pode-se observar que, das 52 gestantes $(28,1 \%)$ em que ocorreu a rotura espontânea das membranas, o tempo de bolsa rota foi menor que 4 horas em 30 gestações $(57,7 \%)$. A mediana do tempo de rotura das membranas foi quatro horas (variação de uma a 36 horas). Quanto à via de parto, foi alta a taxa de cesariana: 84 $(45,4 \%)$ foram eletivas e $63(34,1 \%)$ ocorreram intraparto, totalizando 147 (79,5\%) cesáreas.

Foi realizada análise univariada para estabelecer as comparações entre os possiveis fatores de risco para a transmissão vertical, apresentados na literatura: carga viral na proximidade do parto maior que 1.000 cópias $/ \mathrm{mL}$ (odds ratio $(\mathrm{OR})=0,19$; IC 95\%: 0,01-2,14); contagem materna de linfócitos T CD4+ menor que 200 células $/ \mathrm{mm}^{3}$ (OR=0,17; IC 95\%: 0,59-68,62); não-uso de AZT durante o pré-natal (OR=1,38; IC 95\%: 0,29 - 4,93); não-uso de $A Z T$ durante o parto $(\mathrm{OR}=0,23$; IC 95\%: $0,02-5,97)$; rotura de membranas $(\mathrm{OR}=0,53$; IC $95 \%$ : 0,02 - 4,93); parto vaginal (OR=2,28; IC 95\%: 0,2715,01); baixo-peso ao nascer (OR=1,29; IC 95\%: 0,14-30,37) e recém-nascidos prematuros (OR=1,17; IC 95\%: 0,26-4,77).

A Figura 1 apresenta os esquemas de ARV utilizados durante o pré-natal, nestes dez anos de atendimento de gestantes soropositivas para o HIV. Percebe-se o gradual incremento do esquema tríplice nos últimos anos. Durante este período, 37 gestantes $(20,0 \%)$ utilizaram monoterapia (AZT), $23(12,4 \%)$ receberam esquema duplo (AZT + outro ARV), $121(65,4 \%)$ receberam o esquema tríplice e quatro $(2,2 \%)$ não receberam nenhum anti-retroviral.
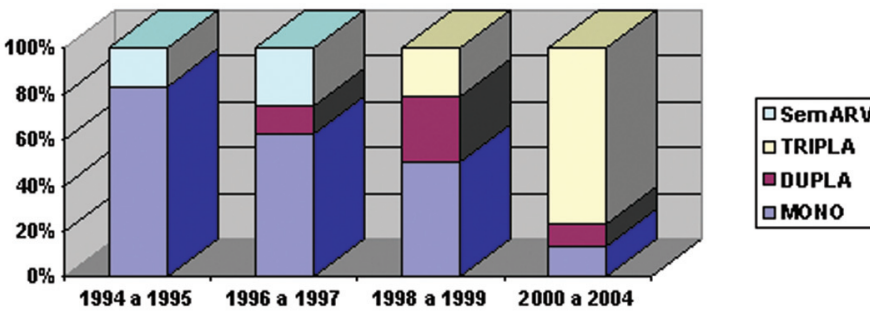

Figura 1 - Percentual dos esquemas (monoterapia, terapia dupla e esquema tríplice) de anti-retrovirais (ARV) administrados durante o pré-natal, por período de ocorrência.
A Figura 2 mostra a distribuição da via de parto ao longo dos anos, percebendo-se o nítido incremento da cesariana a partir de 1999 e o retorno gradual para o parto vaginal a partir de 2003. A mediana do tempo de internação para o parto foi dois dias (variação de um a 12 dias).

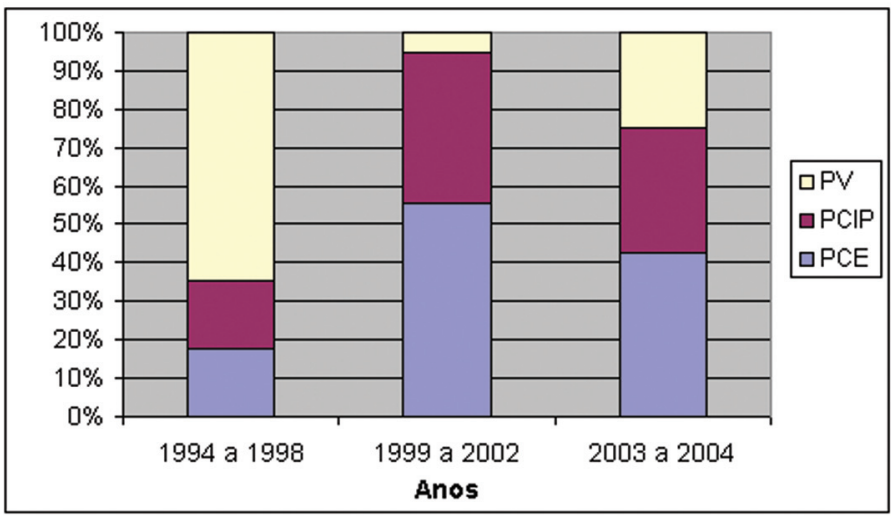

Figura 2 - Percentual da via de parto das pacientes, por período de ocorrência. (PV = parto vaginal; PCIP = cesariana intraparto; PCE = cesariana eletiva).

Na Tabela 2 são apresentados os resultados neonatais: a idade gestacional dos recém-nascidos variou de 27 a 41 semanas, com mediana de 38 semanas (não foi possivel confirmar a idade gestacional de um recém-nascido). Houve 34 prematuros $(18,2 \%)$. O peso ao nascimento variou de 940 a 4.105 gramas (mediana de 2.900 gramas), sendo que 33 recém-nascidos $(19,0 \%)$ apresentaram baixo peso ao nascer. Entre os 188 conceptos houve quatro perdas $(2,2 \%)$ : dois foram natimortos $(1,1 \%)$ e dois $(1,1 \%)$ neomortos. Entre os 186 nascidos vivos, $181(97,3 \%)$ receberam o AZT xarope após o nascimento. O AZT oral não foi administrado em um neomorto que faleceu uma hora após o parto e um neonato de 1994. Nos outros três casos não foi localizada no prontuário médico a prescrição do AZT.

Tabela 2 - Características dos recém-nascidos das gestantes infectadas pelo HIV e a profilaxia neonatal com o AZT.

\begin{tabular}{lcc}
\hline Variáveis & Recém-nascidos $(\mathbf{n})$ & $\%$ \\
\hline Idade gestacional (semanas) & 187 & - \\
$\geq 37$ & 153 & 81,8 \\
$<37$ & 34 & 18,2 \\
$<34$ & 5 & 2,7 \\
$\quad$ Mediana (38 semanas) & 179 & \\
Peso (gramas) & 146 & - \\
$\geq 2500$ & 33 & 81,56 \\
$\quad<2500$ & & 19,0 \\
Mediana (2.900 gramas) & 185 & - \\
AZT oral (xarope) & 181 & 97,8 \\
Sim & 4 & 2,2 \\
Não & 188 & - \\
Recém-nascidos & 184 & 97,8 \\
$\quad$ Vivos & 2 & 1,1 \\
Natimortos & 2 & 1,1 \\
$\quad$ Neomortos & & \\
AZT = zidovudina. & & \\
& &
\end{tabular}


A taxa de transmissão materno-fetal durante o período analisado foi de 3,8\%. Entre os 188 nascimentos, $152(80,9 \%)$ foram definidos como não infectados. Foi confirmada a infecção em seis crianças e ainda existem outras seis em seguimento para definição do seu estado sorológico. A perda de seguimento foi de 10,6\% (20 crianças). Houve quatro óbitos (três perinatais e um após a alta hospitalar, mas com idade não conhecida). As taxas de transmissão vertical do vírus, por periodo, foram: 60\%, até 1996; 28\%, entre 1996 e 1998 ; 0,68\%, entre 1999 e 2004 (Tabela 3).

Tabela 3 - Taxas de transmissão vertical do HIV, por período analisado.

\begin{tabular}{lrrrc}
\hline Período & $\begin{array}{c}\text { Crianças* } \\
\text { (n) }\end{array}$ & & & $\begin{array}{c}\text { Sororevertores Infectados } \\
\text { transmissão } \\
\text { (\%) }\end{array}$ \\
\hline 1994 a 1995 & 5 & 2 & 3 & 60,0 \\
1996 a 1998 & 7 & 5 & 2 & 28,0 \\
1999 a 2004 & 146 & 145 & 1 & 0,68 \\
Total & 158 & 152 & 6 & 3,8 \\
\hline
\end{tabular}

*Total de crianças com sorologia conhecida para o HIV.

Tabela 4 - Características maternas e neonatais das seis crianças que desenvolveram a infecção pelo HIV.

\begin{tabular}{lcccccc}
\hline Variáveis maternas & \multicolumn{7}{c}{ Recém-nascidos } \\
e neonatais & $\mathbf{1}$ & $\mathbf{2}$ & $\mathbf{3}^{*}$ & $\mathbf{4}$ & $\mathbf{5}^{*}$ & $\mathbf{6}^{*}$ \\
\hline Linfócitos T CD4+ (células/mm²) & - & 320 & - & 191 & 400 & 136 \\
Carga viral (cópias/mL) & - & 770 & - & 8.600 & 8.700 & 2.700 \\
AIDS materna & Sim & Não & Não & Não & Não & Sim \\
Início de AZT (semanas) & 31 & 35 & - & 14 & - & - \\
Outros ARV & Não & Não & Não & Não & Duplo Tríplice \\
Rotura de membranas & Não & Sim & Não & Não & Não & Não \\
Tempo de rotura (horas) & - & 4 & - & - & - & - \\
Via de parto & PCTP PCTP PCE & PN & PN & PCE \\
AZT intraparto & Sim & Não & Não & Sim & Sim & Sim \\
Ano do parto & 1995 & 1995 & 1995 & 1997 & 1998 & 2000 \\
Peso ao nascer (gramas) & 3.720 & 3.330 & 1.430 & 3.008 & 3.270 & 3.220 \\
Idade gestacional (semanas) & 40 & 40 & 41 & 40 & 41 & 38 \\
AZT (solução oral para o RN) & Sim & Sim & Sim & Sim & Sim & Sim
\end{tabular}

$\mathrm{AZT}$ = zidovudina; $\mathrm{ARV}=$ anti-retrovirais; $\mathrm{PCIP}=$ cesariana intraparto; $\mathrm{PCE}=$ cesariana eletiva; $P N=$ parto normal; $R N=$ recém-nato. *As mães iniciaram AZT antes da gestação.

A Tabela 4 mostra as características maternas e neonatais das seis crianças infectadas, destacando-se que duas gestantes tinham AIDS, três apresentaram carga viral acima de 1.000 cópias / $\mathrm{mL}$ e duas não tinham carga viral quantificada. Nenhuma das crianças nasceu prematuramente e todas receberam AZT xarope nas primeiras semanas de vida. Somente um recém-nascido apresentou baixo peso.

\section{Discussão}

A atual predominância heterossexual da transmissão do HIV transformou as mulheres no grande grupo de risco para adquirir a infecção. Parcela significativa delas encontra-se em idade reprodutiva e, portanto, a concomitância de uma gestação com a infecção materna pelo HIV não pode ser considerada evento raro ${ }^{4}$. É responsabilidade da equipe de saúde solicitar, o mais cedo possivel, a sorologia para o HIV na gravidez.

No estudo, quase metade $(45,4 \%)$ das pacientes teve confirmação diagnóstica da infecção pelo HIV durante a gestação, o que reforça a recomendação internacional, adotada pelo governo brasileiro, de rastrear o vírus, a infecção em todas as gestantes ${ }^{19}$. Uma série brasileira de gestantes $\mathrm{HIV}$-infectadas demonstrou taxa ainda mais alta (66\%) de diagnóstico da infecção durante a gravide $z^{11}$. Entre as 84 pacientes diagnosticadas durante a gravidez não houve transmissão vertical do HIV. As seis crianças infectadas eram filhas de pacientes com diagnóstico da infecção anterior à gravidez.

A mediana da idade das nossas pacientes (28 anos) e o tempo de estudo (seis anos) não diferiu dos da literatura ${ }^{10,14,16,18}$. União conjugal estável foi o achado predominante $(65,4 \%)$, concordante com série de casos publicada anteriormente ${ }^{9}$, mas em discordância de outra série, onde $82,8 \%$ das mulheres HIV-positivas eram solteiras ${ }^{18}$.

O uso de ARV durante a gestação vem sendo recomendado desde meados da década de 90 , a partir de estudo pioneiro que demonstrou a eficácia da monoterapia com zidovudina na redução da transmissão vertical do HIV ${ }^{2}$. Atualmente é indiscutivel a ação benéfica destes medicamentos na redução da transmissão, e o esquema mais preconizado é a associação de três tipos de ARV para potencializar ao máximo os seus efeitos e reduzir a carga viral a niveis indetectáveis durante a gravide $^{3,7,20}$. Praticamente todas as nossas gestantes fizeram uso dos ARV, com diferentes esquemas terapêuticos, o mesmo tendo ocorrido em casos de outras séries brasileiras recentemente publicadas $^{10,11}$, o que demonstra que estamos acompanhando os resultados dos países desenvolvidos. Grandes séries de pacientes acompanhadas em todo o mundo mostraram variações entre 90 e 100\% de administração dos ARV durante a gestação ${ }^{15,21}$.

A administração por infusão venosa de AZT durante o parto é outro fator importante para a proteção do feto. Vários registros confirmam a redução da transmissão vertical com o uso profilático 
dos ARV somente no período intraparto e/ou no neonatal ${ }^{3}$. Destacamos que $8,8 \%$ das nossas parturientes não receberam o medicamento endovenoso. O motivo principal para explicar a falha na administração de AZT intraparto foi a admissão da paciente em período expulsivo, não havendo tempo suficiente para aplicar o medicamento. O mesmo ocorreu em outra série de casos de gestantes HIV-positivas no Brasi1 ${ }^{10}$. No momento, o Ministério da Saúde tem procurado oferecer teste rápido para o HIV à admissão nas maternidades para pacientes que não foram testadas durante a gravidez. Para as parturientes com sorologia positiva é recomendada a infusão venosa de AZT até a ligadura do cordão umbilical e a administração do xarope ao recém-nascido, com suspensão do aleitamento materno ${ }^{19}$.

Os esquemas de ARV utilizados neste período mostram a transição do uso profilático de AZT (monoterapia) para a terapia tríplice. Até meados de 1999, AZT era o único medicamento recomendado pelo Ministério da Saúde para a profilaxia da transmissão vertical do HIV. A partir deste ano houve gradual substituição da monoterapia pelo esquema tríplice, conforme recomendação da Coordenação Nacional de DST/AIDS. Em nossa série é evidente a utilização da terapia tríplice em substituição à monoterapia após 1999, sendo que no período de 2000 a $2004,79,6 \%$ das gestantes receberam o esquema triplice e apenas $13,5 \%$ receberam monoterapia. A escolha dos medicamentos, o momento de introdução, o tempo de uso e o monitoramento dos efeitos adversos são variáveis importantes para impedir a toxicidade materna e neonatal. O uso dos ARV é apenas um componente dos cuidados pré-natais às gestantes infectadas pelo HIV, que demandam também maior atenção no diagnóstico de co-morbidades como anemia, má nutrição, uso de álcool ou drogas, doenças co-existentes (hepatites, infecções genitais, diabetes) e outras afecções ${ }^{4}$.

Pequena proporção de nossas gestantes $(14,3 \%)$ apresentou contagem de linfócitos T CD4+ inferior a 200 células $/ \mathrm{mm}^{3}$, indicando ausência de comprometimento imunológico grave, em concordância com o European Collaborative Study ${ }^{16}$. Contudo, em outros estudos, a proporção de mulheres com contagem de linfócitos T CD4+ abaixo deste valor foi mais elevada, variando de 22 a $29 \%{ }^{15,22}$. Os estudos nacionais não fazem referência a estes valores de linfócitos T CD4+. A baixa contagem materna de linfócitos T CD4+ tem sido associada à transmissão vertical do $\mathrm{HIV}^{6,7}$.

A carga viral inferior a 1.000 cópias $/ \mathrm{mL}$ tem sido o ponto de corte adotado para o parto vaginal. No estudo WITS (Women and Infants Transmission
Study Group) foi avaliada a relação entre a carga viral materna e o risco de transmissão vertical do HIV. Analisando os resultados de 552 gestantes, observaram-se percentuais diferenciados de transmissão, confirmando maior risco de transmissão com o incremento da carga viral. Neste estudo não houve transmissão vertical quando as gestantes apresentavam carga viral de 1.000 cópias $/ \mathrm{mL}$ nas proximidades do parto ${ }^{5}$. Estudos posteriores demonstraram que a transmissão pode ocorrer em até $1 \%$ dos neonatos cuja mãe apresente carga viral menor que 1.000 cópias $/ \mathrm{mL}$. Para estes autores o objetivo do uso profilático dos ARV deve ser suprimir a replicação do vírus durante a gestação ${ }^{23,24}$. Em nosso estudo, 60,4\% das pacientes com carga viral próxima ao parto apresentaram niveis inferiores a 1.000 cópias $/ \mathrm{mL}$. Dentre estas pacientes houve um recém-nascido infectado, mas pode-se observar que houve outros fatores de risco para a transmissão (início tardio de AZT, rotura de membranas, não-uso de AZT intraparto). Entre as mulheres com carga viral indetectável não houve transmissão vertical do vírus.

Metanálise envolvendo 4.721 gestantes confirmou que o tempo de duração da rotura das membranas está diretamente associado ao risco de transmissão do vírus. Para cada hora a mais de duração do tempo de rotura das membranas houve incremento de $2 \%$ de recém-nascidos infecta$\operatorname{dos}^{25}$. Em nossa série de casos uma gestante que apresentou rotura de membranas com duração de quatro horas, e foi submetida à cesariana, teve seu neonato infectado.

Sabemos também que o tipo de parto está associado ao risco de transmissão. Metanálise publicada em 1999, envolvendo 8.533 pares de mães e filhos, encontrou decréscimo pela metade do risco de transmissão entre as mulheres que foram submetidas à cesariana eletiva. Quando a cesárea eletiva foi associada ao uso de ARV materno e neonatal, a taxa de transmissão foi reduzida para $2 \%^{8}$.

Questionam-se atualmente os beneficios da cesariana eletiva quando a carga viral materna está indetectável, tendo em vista que o risco de transmissão é inferior a $2 \%$ para as mulheres que usam esquema tríplice de ARV durante o pré-natal e seguem o protocolo 076 no parto e no recémnascido ${ }^{24}$. O Ministério da Saúde, à semelhança dos países desenvolvidos, recomenda a cesariana eletiva com 38 semanas completas em todas as mulheres com carga viral superior a 1.000 cópias / $\mathrm{mL}$, determinada a partir de 34 semanas, ou naquelas em que este parâmetro laboratorial não estiver disponivel. Para mulheres com carga viral inferior a 1.000 cópias $/ \mathrm{mL}$, aferida a partir de 34 
semanas de gestação, a via de parto é por indicação obstétrica, conduta que temos adotado ${ }^{19}$. Nossos resultados mostram que, entre os seis neonatos infectados, dois nasceram por cesariana eletiva, dois por cesariana intraparto e dois nasceram por via vaginal.

Em nossa amostra foi alta a taxa de cesariana. Isto se deve a vários fatores, sendo que os dois principais foram a carga viral superior a 1.000 cópias $/ \mathrm{mL}$ na época do parto $(37 \%)$ e a cesárea iterativa (28,5\%). Além disso, no período de 1999 a 2002, seguindo a literatura ${ }^{8}$, a infecção pelo HIV era, por si só, indicação de parto por via abdominal em nosso serviço. A partir de 2003 passamos a utilizar a carga viral quantificada após 34 semanas de gestação como determinante na escolha da via de parto. Na Figura 2 podemos perceber nitido incremento de partos vaginais, sem aumento da transmissão vertical, a partir de 2003, o que significa que essas gestantes apresentavam baixa carga viral e que seus recém-nascidos receberam AZT oral no período neonatal.

Estudo multicêntrico (Pediatric AIDS Clinical Trials Group 185 Team $^{22}$, incluindo recém-nascidos cujas mães estavam em uso de zidovudina profilática - ou outros ARV - demonstrou que 497 recém-nascidos tiveram taxas de prematuridade (17\%), baixo peso ao nascer (13\%) e CIUR (6\%) muito semelhante às de crianças de mulheres não infectadas, que também haviam recebido cuidados pré-natais adequados. Lembram que os outros estudos que apresentaram resultados neonatais desfavoráveis para os recém-natos de mulheres HIV-infectadas não levaram em consideração o fato de não ter havido tratamento ARV profilático naquelas pacientes. Levantam a hipótese de que os ARV, além de reduzir a transmissão vertical do virus na medida em que melhoram as condições maternas, possibilitam melhores resultados neonatais ${ }^{14}$.

A freqüência de parto pré-termo relatada na literatura, em mulheres infectadas pelo HIV usando ARV, variou de 13 a $17 \%{ }^{15,18}$. Nas séries brasileiras os resultados foram bastante diversos: a taxa de prematuridade variou de $6,8^{10}$ a $32 \%{ }^{9}$. Nossos resultados para o parto pré-termo foram semelhantes aos dos países desenvolvidos: 18,2\% nasceram prematuros, taxa muito semelhante à média da nossa maternidade, que nesse período foi de $17,8 \%$. A freqüência de recém-nascidos com baixo peso ao nascer na literatura variou de 9 a $16 \%{ }^{15}$. Somente em uma das séries brasileiras esta variável foi analisada, tendo sido de $11,7 \%^{10}$. Assim, tivemos taxa ligeiramente maior de recém-natos com baixo peso ao nascer, comparada às da literatura: $19,0 \%$. Esta taxa, contudo, não difere da taxa média da nossa maternidade que, nesse periodo, foi de $18,6 \%$.

As taxas de transmissão vertical na literatura variaram entre 0 e 25,0\%, na dependência de fatores de risco maternos e/ou neonatais. Entre os fatores de risco maternos são citados: nãoutilização dos ARV, parto vaginal ou instrumental, maior tempo de duração da rotura das membranas, carga viral elevada, baixa contagem de células T CD4+ e aleitamento materno. Entre as variáveis neonatais associadas ao maior risco de transmissão são citados o baixo peso ao nascer e a prematuridade $8-11,22,23$. Devido, provavelmente, ao pequeno número de crianças infectadas na nossa série de casos, não foi encontrada nenhuma associação significante entre os fatores de risco analisados e a transmissão vertical. A taxa de transmissão vertical global encontrada no nosso estudo foi de 3,8\%. Ressaltamos que, a partir de 2001, não tivemos mais nenhum caso de transmissão materno-fetal do vírus. Em nossa série, apenas um neonato infectado apresentava baixo peso ao nascer (1.430 g), e nenhum deles era prematuro. Encontramos um prematuro extremo (27 semanas de gestação) em 2003, com peso ao nascer de 940 gramas, que apresentou sorologia negativa para o HIV durante seu seguimento.

O presente estudo demonstra que a adoção de condutas adequadas durante a gestação, parto e puerpério são determinantes na redução da transmissão vertical do HIV. Embora não tenha sido possivel a confirmação estatística dos fatores de risco para transmissão, em decorrência do pequeno número de crianças infectadas, é possível que o início tardio de ARV, a carga viral materna elevada próximo ao parto e o baixo peso ao nascer sejam fatores importantes nessa transmissão.

\section{Referências}

1. UNAIDS [homepage on the Internet]. AIDS epidemic update 2004 [cited 2005 Feb 23]. Available from: http://www.unaids.org/wad2004/report_pdf.html.

2. Connor EM, Sperling RS, Gelber R, Kiselev P, Scott G, O'Sullivan MJ, et al. Reduction of maternalinfant transmission of human immunodeficiency virus type 1 with zidovudine treatment. Pediatric AIDS Clinical Trials Group Protocol 076 Study Group. N Engl J Med. 1994;331(18):1173-80.

3. Watts DH. Management of human immunodeficiency virus infection in pregnancy. $\mathrm{N}$ Engl $\mathrm{J}$ Med. 2002;346(24):1879-91.

4. Minkoff H. Human immunodeficiency virus infection in pregnancy. Obstet Gynecol. 2003;101(4):797-810. 
5. Garcia PM, Kalish LA, Pitt J, Minkoff H, Quinn TC, Burchett SK, et al. Maternal levels of plasma immunodeficiency virus type 1 RNA and the risk of perinatal transmission. Women and Infants Transmission Study Group. N Engl J Med. 1999;341(6):394-402.

6. Abrams EJ. Prevention of mother-to-child transmission of HIV: successes, controversies and critical questions. AIDS Rev. 2004;6(3):131-43.

7. Magder LS, Mofenson L, Paul ME, Zorrilla CD, Blattner WA, Tuomala RE, et al. Risk factors for in utero and intrapartum transmission of HIV. J Acquir Immune Defic Syndr. 2005;38(1):87-95.

8. The International Perinatal HIV Group. The mode of delivery and the risk of vertical transmission of human immunodeficiency virus type 1: a metaanalysis of 15 prospective cohort studies. N Engl J Med. 1999;340(13):977-87.

9. Tess BH, Rodrigues LC, Newell ML, Dunn DT, Lago TD. Breastfeeding, genetic, obstetric and other risk factors associated with mother-to-child transmission of HIV-1 in Sao Paulo State, Brazil. Sao Paulo Collaborative Study for Vertical Transmission of HIV-1. AIDS. 1998;12(5):513-20.

10. Nogueira SA, Abreu T, Oliveira R, Araujo L, Costa $\mathrm{R}$, Andrade M, et al. Successful prevention of HIV transmission from mother to infant in Brazil using a multidisciplinary team approach. Braz J Infect Dis. 2001;5(2):78-86.

11.João EC, Cruz ML, Menezes JA, Matos HJ, Calvet GA, d'Ippolito MM, et al. Vertical transmission of HIV in Rio de Janeiro, Brazil. AIDS. 2003;17(12):1853-6.

12. Newell ML, Coovadia H, Cortina-Borja M, Rollins N, Gaillard P, Dabis F, et al. Mortality of infected and uninfected infants born to HIV-infected mothers in Africa: a pooled analysis. Lancet. 2004;364(9441):1236-43.

13. Minkoff $H$, Hershow $R$, Watts $D H$, Frederick M, Cheng I, Tuomala $\mathrm{R}$, et al. The relationship of pregnancy to human immunodeficiency virus disease progression. Am J Obstet Gynecol. 2003;189(2):552-9.

14. Lambert JS, Watts DH, Mofenson LM, Stiehm ER, Harris DR, Bethel J, et al. Risk factors for preterm birth, low birth weight and intrauterine growth retardation in infants born to HIV-infected pregnant women receiving zidovudine. AIDS. 2000;14(10):1389-99.
15. Tuomala RE, Shapiro DE, Mofenson LM, Bryson Y, Culnane M, Hughes MD, et al. Antiretroviral therapy during pregnancy and the risk of an adverse outcome. N Engl J Med. 2002;346(24):1863-70.

16. European Collaborative Study. Swiss Mother and Child HIV Cohort Study. Combination antiretroviral therapy and duration of pregnancy. AIDS. 2000:14(18):2913-20.

17. Brocklehurst P, French R. The association between maternal HIV infection and perinatal outcome: a systematic review of the literature and metaanalysis. Br J Obstet Gynaecol. 1998;105(8):836-48.

18. Ellis J, Williams H, Graves W, Lindsay MK. Human immunodeficiency virus infection is a risk factor for adverse perinatal outcome. Am J Obstet Gynecol. 2002;186(5):903-6.

19. Ministério da Saúde. Secretaria de Vigilância Sanitária em Saúde. Programa Nacional de DST e AIDS. Recomendações para a profilaxia da transmissão materno-infantil do HIV e terapia antiretroviral em gestantes. Brasília: Ministério da Saúde; 2004

20. Brocklehurst P, Volmink J. Antiretrovirals for reducing the risk of mother-to-child transmission of HIV infection. Cochrane Database Syst Rev. 2005;(1):CD003510.

21. European Collaborative Study. Exposure to antiretroviral therapy in utero or early life: the health of uninfected children born to HIV-infected women. J Acquir Immune Devic Syndr. 2003;32(4):380-7.

22. Mofenson LM, Lambert JS, Stiehm ER, Bethel J, Meyer WA 3rd, Whitehouse J, et al. Risk factors for perinatal transmission of human immunodeficiency virus type 1 in women treated with zidovudine. Pediatric AIDS Clinical Trials Group Study 185 Team. N Engl J Med. 1999;341(6):385-93.

23. Ioannidis JP, Abrams EJ, Ammann A, Bulterys M, Goedert JJ, Gray L, et al. Perinatal transmission of human immunodeficiency virus type 1 by pregnant women with RNA virus loads $<1000$ copies $/ \mathrm{ml}$. J Infect Dis. 2001;183(4):539-45.

24. Cooper ER, Charurat M, Mofenson L, Hanson IC, Pitt J, Diaz C, et al. Combination antiretroviral strategies for the treatment of pregnant HIV-1infected women and prevention of perinatal HIV-1 transmission. J Acquir Immune Defic Syndr. 2002;29(5):484-94.

25. International Perinatal HIV Group Duration of ruptured membranes and vertical transmission of HIV-1: a meta-analysis from 15 prospective cohort studies. AIDS. 2001;15(3):357-68. 